\title{
Homossacralidade como regime de sujeição das vidas bichas
}

\author{
Rick Afonso-Rocha ${ }^{1}$
}

Resumo: Desde que comecei minhas pesquisas sobre a significação do corpo bicha durante a ditadura cis-hétero-militar brasileira, como a denomino, o pensamento do filósofo italiano Giorgio Agamben me serviu como suporte analítico. Por um tempo, pareceu-me que a análise agambeniana, sobretudo aquela sobre o homo sacer, constituía uma ferramenta interessante para pensar as existências bichas sob os anos de chumbo. Contudo, quanto mais levava em consideração essas singularidades, mais percebia as incoerências da minha frustrada tentativa de subsunção. Com o tempo, pude constatar que Agamben deixava escapar as particularidades sociais inerentes à declaração, pelo Soberano, da nudez de uma vida. Em sua leitura, o homo sacer seria universal: todos poderíamos ser abandonados ou sacralizados pelo Soberano. Sua generalização apagava as marcas dos processos que separam os corpos destinados a viver, daquelas corporalidades marcadas como vidas sem importância. Ou melhor, corpos passíveis de serem expostos à possibilidade da morte, inclusive violenta, cujas mortes não despertam luto ou compaixão social. Agamben desprezava a gestão deimo-bio-necropolítica dos indesejados, de modo tal que o lugar do qual falava aparecia, embora à revelia: homem, cis, hétero, branco, ocidental. Habitando uma zona de inteligibilidade, falta ao teórico um olhar mais atento para os sujeitos concretos. Em direção outra, para pensar as singularidades em relação às existências bichas durante o contexto cis-hétero-ditatorial, formulei a noção de "homossacralidade", como regime de sujeição atrelado ao paradigma de governamento da deimopolítica. Para demarcar essas especificidades, traço, provisória e imaginariamente, um quadro sobre as diferentes formações históricas de significação da dissidência sexo-gendrada no Brasil.

Palavras-chave: Deimopolítica. Biopolítica. Necropolítica

\footnotetext{
${ }^{1}$ Uma bicha nordestina: doutoranda e mestra pelo PPGL: Linguagens e Representações, da Universidade Estadual de Santa Cruz (PPGL/UESC). Bolsista da FAPESB. Integrante do grupo de pesquisa "O Espaço Biográfico no Horizonte da Literatura Homoerótica" (GPBIOH), do Núcleo de Estudos Queer e Decoloniais da UFRPE (NuQueer) e do Grupo de Pesquisa Estudos Literários Contemporâneos: Fontes da Literatura de Jornal da UEFS. Colaboradora do Grupo de Estudos Discursivos em Arte e Design (NEDAD/UFPR), do Grupo de Estudos Discursivos da UESC (GED) e do blog Resista! Observatório de Resistências Plurais. E-mail: rarocha@uesc.br
}

Vol. 04, N. 13, Jan. - Abril, 2021 - http://periodicoscientificos.ufmt.br/ojs/index.php/rebeh/index 
Introdução

A análise de Agamben (2007) sobre a figura do homo sacer auxiliou-me a refletir sobre como os sujeitos inscritos em práticas cis-heterodissidentes foram, durante o contexto ditatorial brasileiro (1964-1988), ainda mais marginalizados e destituídos da condição mínima de existência humana (se é que essa existia para essas vidas). Como esses corpos não gozavam de importância, na prática, quem os matassem não poderia ser enquadrado na legislação penal. Contaria, antes, com a impunidade garantida pelo Estado.

O homo sacer, também chamado de vida nua, homem sagrado ou homem abandonado, na leitura agambeniana (2007), não mais gozava da proteção do Estado de direito. Assim como Pôncio Pilatos, o Soberano lavava suas mãos para se purificar do sangue reiteradamente derramado. Para Agamben (2007), é essa a condição dos sujeitos na contemporaneidade. Todos nós somos, em alguma medida, candidatos em potência a habitarmos essa zona de indeterminação. Sem grandes exceções, haveria uma sacralidade universal em latência à espera da decretação pelo Soberano. Qualquer um poderia, assim, ser marcado como inimigo social, tendo sua nudez exposta, de acordo com tal perspectiva.

Ainda que queira Agamben (2007), o homo sacer não se trata de um sujeito fixo, universal, afinal "nem todas as vidas são nuas. Algumas nascem para viver, outras se tornam vidas matáveis [...]" (BENTO, 2018, p. 4). O corpo do dito inimigo só se constitui pelas suas marcas, pelo seu real, pelos sentidos insuportáveis que nele se inscrevem sócio-historicamente.

Como efeito dessa pretensa universalização, apesar de realizar uma análise profunda sobre a politização da vida no Ocidente a partir do paradigma da tanatopolítica, Agamben silencia, por exemplo, a história da colonização (PEREIRA, 2015). Com isso, acaba apagando as diferenças materiais responsáveis pela sacralização de uma vida, isto é, pela declaração de sua suposta condição de homo sacer.

As singularidades materiais desprezadas por Agamben mostram-nos que não há, em si, uma declaração de sacralidade. Ou seja, as vidas, amplamente consideradas, 
não são "tornadas" vulneráveis. São, em verdade (algumas delas), desde sempre, produzidas como corporalidades passíveis de serem violentadas, mortas, vilipendiadas, vidas destinadas à abjeção. A sacralização não constitui, para a maioria dos corpos marcados como inimigos, um processo ocasional e a posteriori. Pelo contrário, a sacralização de uma vida, no mais das vezes, impõe-se como uma "herança" irrenunciável de classe, gênero, raça, sexo, religião. Os processos de declaração de sacralidade são, para essas existências, procedimentos de reiteração e conservação da vulnerabilidade "pré-existente", visando a sua manutenção em relação àqueles sujeitos que compartilham certas identificações. Para esses corpos, a sacralidade não é uma promessa, mas uma realidade diariamente concretizada pela citacionalidade e recursividade do poder.

O tornar-se homo sacer, de forma indiscriminada, constitui uma ficção que existe apenas na cabeça dos intelectuais cis, hétero, brancos e de classe média. Nas periferias "terceiro-mundistas", a sacralidade se confunde com a própria existência; resguardadas, evidentemente, as singularidades decorrentes das múltiplas contradições que nos atravessam (gênero, raça, classe, religião etc.).

Há corpos reiteradamente marcados como corporalidades destinadas a viver, ao passo que há corpos reiteradamente produzidos como vidas destinadas à morte, às violências e ao sofrimento. Inclusive, gozar da possibilidade de desprezar esse fato é, em si, um privilégio. Afinal, para aqueles que são produzidos como inimigos sociais, a possibilidade da morte, seja ela biológica, social, simbólica ou cultural, lança-os à insuperável dimensão afetiva da angústia. ${ }^{2}$ Somos obrigados a pensar a possibilidade, cada vez mais concreta, de nossa própria morte como efeito da sacralização, isto é, por habitarmos a zona de ininteligibilidade.

\section{Mutilações nos corpos bichas}

\footnotetext{
2 Aqui, tomo o conceito de angústia em Heidegger (1989) como tonalidade afetiva (Befindlichkeit) que direciona o Dasein (ser-aí), ser do ente humano, e abre-lhe o mundo, ao sem-sentido, pondo-o em suspensão ante o nada.
}

Vol. 04, N. 13, Jan. - Abril, 2021 - http://periodicoscientificos.ufmt.br/ojs/index.php/rebeh/index 
Para acentuar a singularidade da declaração de sacralidade sobre os corpos bichas $^{3}$ durante o contexto ditatorial, formulei o termo homossacralidade (AFONSOROCHA, 2020). Sublinho, com isso, que, conforme Agamben (2007), o risco potencial, a que todos supostamente estaríamos submetidos, em sermos declarados homo sacer, foi diariamente atualizado na ditadura cis-hétero-militar brasileira quando direcionado às vidas bichas, ainda que resguardadas as singularidades que atravessavam tais corpos. $\mathrm{O}$ estilo e a ética de vidas bichas se proclamaram "sagrados"; sujeitos cisheterodissidentes, declarados descartáveis. A experiência ditatorial brasileira particularizou a universalidade da figura do homo sacer, transfigurando-a no regime de sujeição da homossacralidade.

É preciso sinalizar que os efeitos da sacralização foram sentidos de formas diferentes a depender da confluência entre os distintos regimes de sujeição pelos quais esses corpos eram constituídos. Se bichas, efeminadas, periféricas e negras, então os efeitos da sacralidade se demonstravam muito mais danosos do que, por exemplo, em relação aos corpos das "bichas" brancas, de classe média, cis, burguesas. Com isso, busco afirmar a existência de outros regimes de assujeitamento específicos que funcionaram durante a ditadura brasileira, cujos efeitos não podem ser desprezados no funcionamento sociopolítico da homossacralidade. A articulação de variadas e complexas tecnologias políticas intensificou a produção de outros sujeitos como inimigos imaginários da nação: negros, comunistas, mulheres, camponeses, indígenas. Dessa forma, quando tais marcadores sociopolíticos se interseccionalizavam em um mesmo sujeito, a exemplo das lésbicas comunistas ou das bichas negras periféricas, qualquer tentativa de equacionalização entre as distintas opressões se desvela como pura violência simbólica, fincada na fantasia da homogeneidade que ainda hoje busca legitimar a ficção das "homossexualidades".

\footnotetext{
3 Por bicha, entendo uma relação territorial de contestação simbólica do imperativo cisgênero e heterossexual. Poderia ainda dizer que é uma redução da formulação bichasapatrans (maribollotrans), de Paco Vidarte (2019). O termo não diz apenas daquelas existências homossexuais masculinas, mas sinaliza para as vidas animalizadas (bicha = verme intestinal, viado ou sapatão que em sua forma mais usual torna-se sapa) e não assimiladas pela norma cissexista. Claro que essa não-assimilação é sempre circunstancial, nunca apriorística. Afinal, estamos todas a dançar com o poder. Ou, dito de outro modo, o poder é a própria dança. Não há resistência pura e sem contaminação. Não há, da mesma parte, funcionamento do poder extrínseco à resistência.
}

Vol. 04, N. 13, Jan. - Abril, 2021 - http://periodicoscientificos.ufmt.br/ojs/index.php/rebeh/index 
Nesse sentido, podemos citar que a categoria homo sacer teria implicações de gênero negligenciadas por Agamben, como pontuou Ronit Lentin (2006) ao postular a mulher como femina sacra, para acentuar que, em razão da sua suposta função como veículo de limpeza étnica (reprodução controlada) e de sua vulnerabilização sexual e de gênero, o corpo dito feminino foi produzido, ao longo da história, como vida à mercê do poder Soberano: aquela que pode ser morta, violentada, ou, em alguns casos, engravidada, sem que tais atos provoquem compaixão real no corpo social, de modo a garantir a impunidade, ao mesmo tempo que produz o corpo "feminino" como uma ameaça à sociedade. Produção necessária à manutenção do poder masculino e da própria configuração capitalística (que é, em alguma medida, um sistema à imagem e semelhança do patriarcado). Para evidenciar esse funcionamento da sacralidade em relação aos corpos lidos como femininos na ditadura de 1964, devemos refletir sobre o fato de que, naquele período ditatorial, as mulheres guerrilheiras sofreram violência sexual e de gênero, além das violências sofridas pelos homens. ${ }^{4}$

Em sentido semelhante, notou Ewa Płonowska Ziarek (2008) que, embora os exemplos usados por Agamben em relação às vidas efetivamente nuas sejam recortados e diferenciados por questões de raça, gênero, sexualidade e classe, sua análise acaba desprezando essa heterogeneidade, de modo a desconsiderar tais configurações da biopolítica na declaração da sacralização.

Com vistas a indiciar os contornos dessas configurações durante a última ditadura, bem como de seu entrecruzamento, cito trecho do depoimento de Deco, identificado como "bailarino e transexual", ao jornal Afinal, de Florianópolis, $\mathrm{n}^{\mathrm{o}} 12$, maio de 1981, na matéria "O golpe da princesinha", sobre a comemoração do $93^{\circ}$ aniversário da abolição da escravatura. Vejamos:

\begin{abstract}
Eles pensam por ser negro tenho de ser maconheiro, marginal, prostituto e viado sem vergonha. A violência é tanta que até desperta dentro da gente coisas que a cabeça nem imagina. Já assisti homossexuais brancos desacatar e até mesmo agredir policiais sem que lhes acontecesse nada. Recentemente fui preso quando me dirigia à casa de um amigo meu sem que nada tivesse cometido. Como me neguei a entrar na viatura os 'ratos' me encheram de porrada. (p. 12).
\end{abstract}

\footnotetext{
${ }^{4}$ Vide: [Izabel Fávero, depoimento à CNV, em 27 de abril de 2013. Arquivo CNV, 00092.000088/201491.] (BRASIL, 2014).
}

Vol. 04, N. 13, Jan. - Abril, 2021 - http://periodicoscientificos.ufmt.br/ojs/index.php/rebeh/index 
$\mathrm{Na}$ matéria, assinada por Flávio Carvalho, é dito que Deco "Repudia a sociedade hipócrita que trata com condescendência o homossexual branco e despreza o homossexual negro" (p. 18). Como podemos observar, o depoimento de Deco denuncia as diferenças entre ser bicha branca e ser bicha negra durante a ditadura. Disso resulta que, caso levemos em consideração esse indício e confrontemo-lo com outros episódios, seremos impossibilitados de equacionar experiências tão distintas, ainda que vivenciadas por sujeitos lidos como bichas.

De certo modo, esse vestígio coloca-nos em posição de suspeita em relação às análises que se fundam, ao mesmo tempo em que reforçam a existência de uma mesma experiência de opressão vivida por todas as bichas, indiscriminadamente, decorrente de uma "homofobia universal".

Para além da repetição acadêmica e militante exaustiva de que nossas sociedades são homofóbicas, devemos empreender esforços para compreender as singularidades dos distintos regimes de sujeição em relação aos corpos e sujeitos bichas. Para, assim, demarcar, não uma continuidade casuística que remontaria ao período colonial, ou pior, remontaria ao período helênico e explicaria o atual estágio das coisas, mas suas descontinuidades e singularidades. Interessa-me pensar o que houve de particular e singular na ditadura brasileira em relação aos sujeitos LGBT + . Para isso, faz-se preciso desvincular-nos de uma suposta experiência universal da homofobia, fincada na dimensão individualista e não no funcionamento sócio-político em si, este último considerado a partir do paradigma da ruptura.

A partir disso, entendo que o homo sacer nunca existiu. $\mathrm{O}$ que, de fato, existem são os processos de sacralização que produzem determinados corpos como importantes e outros como corporalidades sem importância ou reiteram essa "condição", garantindo sua permanência. É por meio do regime de sacralidade que lemos/reconhecemos a "humanidade", ou melhor, o "peso" de determinados sujeitos, em detrimento de outros que são jogados numa zona de ininteligibilidade. É disso que Butler $(2015 ; 2019)$ falou quando analisara as vidas não passíveis de luto. Não existem vidas matáveis em si, o que existem são processos historicamente situados de animalização de certos sujeitos, tornando-os matáveis e sem importância ou perpetuando essa "condição" por sucessivos procedimentos de sacralização. Tais processos produzem a inevitabilidade do "destino" 
mortífero: naturalizamos que a vida sem dignidade e a morte violenta são o fim esperado e, talvez, justo para determinados sujeitos.

Peço licença ao leitor para narrar duas situações autobiográficas que põem em jogo a produção do inevitável destino severino. Lembro, com certa tristeza, de meu avô, neto de escravizados, homem negro, do campo, que estudou até a $4^{\text {a }}$ série do fundamental I, falando: “eu nasci para sofrer", sempre que se deparava com alguma adversidade. Era a ritualística que ele havia "criado", ou que haviam criado nele, para "aceitar" pacificamente as injustiças sociais pelas quais passou (sequer conseguia visualizar como violências). Dessa forma, naturalizava suas explorações e podia viver mais um dia.

O outro episódio, vivi aos 12 anos de idade. Eu e alguns primos estávamos brincando no quintal da casa de meus avós. De repente, pelo que consigo recordar, sugeri que cada um falasse o que sonhava em se tornar quando crescesse, afinal sempre víamos essas cenas em filmes e nos programas de televisão. Meus primos, todos negros, simplesmente não tinham sonhos. $\mathrm{O}$ único que respondeu a minha pergunta, um que desde os 10 anos trabalhava como auxiliar de pedreiro com o pai, disse-me: "acho que serei meu pai". Quando eu, o único branco, falei que seria biólogo, todos riram: "Rick, você é neto de pedreiro, cai na real", disse lucidamente meu primo mais velho. Hoje, não consigo parar de pensar naquele dia. Meu primo realmente se tornou seu pai. Nenhum deles pôde cursar o ensino superior, eu fui a única “exceção". Embora pobre e, anos mais tarde, bicha, carrego o privilégio da branquitude. Carrego, ainda que de forma limitada, a possibilidade de sonhar com uma vida mais ou menos digna. Descobri que “cair na real” era uma obrigação dura daqueles que não gozavam de nenhum privilégio.

Fecho o parêntese.

Levando em consideração as particularidades das políticas sexuais e de gênero, entendo que, na ditadura cis-hétero-militar, em se tratando de vidas bichas, preservados seus atravessamentos constitutivos, não podemos falar de vidas matáveis, mas, corriqueira e reiteradamente, violentadas e/ou mortas. A potência se transformou em atos, numa política assumida pelo regime ditatorial, por meio da produção do cisheterodissidente como vida sem atributos específicos de humanidade. 
O prefixo homo foi "escolhido" por traduzir certa ambiguidade em relação ao sentido de humanidade, aqui postulada como efeito do projeto colonialista, pondo em jogo, com isso, aquele resto não incorporado (nem homem, nem besta) produzido como inimigo social, necessário, frise-se, à justificação do fundamento da autoridade. Ambiguidade também em relação ao sentido de homossexual, em sua dimensão ampla, como esse é utilizado em conceitos como homoafetivo, homotextualidade etc.

Com o termo homossacralidade, busco contornar a disjunção adjetivosubstantiva do conceito homo sacer que, indistintamente, aponta para o sujeito universal como produto da sacralização, desconsiderando o processo. Assim, enfatiza-se a transmutação do sujeito universal sacralizado em múltiplos procedimentos de sujeição. A acreção sufixal traduz a situacionalidade material e as circunstâncias singulares dessa declaração, levando em consideração os marcadores materiais negligenciados por Agamben, bem como apontando para outros regimes de sujeição, como aquele sinalizado por Deco, com recortes raciais. Do produto ao processo. Do sujeito aos mecanismos de sujeição. Do global ao local. Do universal ao específico. Do macro ao micro.

O conceito de Agamben, quando não produz um sujeito universal igualmente exposto, desconsiderando suas condições materiais, acaba essencializando o processo mutilatório, de modo a produzir uma identidade sacer aprioristicamente naturalizada (a precariedade da vida como experiência universal). Aspecto que reforça a dita livre sujeição, dando força à narrativa da intransponibilidade das opressões.

De certo modo, a formulação homossacralidade visa a deslocar a ideia eurocêntrica e universalista de homo sacer - limitada ao horizonte referencial de seu autor: europeu, colonialista, branco, cis, hétero, masculino. Como destacou Pedro Gomes Pereira (2015), Agamben não questionou as singularidades dos atores declarados como sagrados, de modo que raça, etnia, classe social, gênero, sexualidade não foram problematizados ou pensados como parte da vida. Agamben não pensou o homo sacer em suas dimensões sociopolíticas e materiais, incluindo nisso, necessariamente, sua inscrição em relações de poder pós-coloniais (DE OTO; QUINTANA, 2010). 
A propositura dessa dimensão real do homo sacer, a partir do contexto ditatorial brasileiro, confronta e questiona a condição potencial masculina, ocidental e cisgênero-heterossexual daquele. A quem se direcionavam as políticas de extermínio e violência? Quais sujeitos tiveram o rótulo de perigosos e quais receberam a proteção e a compaixão social? Sob a universalidade do homem sagrado, os corpos que importam se potencializaram, enquanto as diferenças foram homogeneizadas, violentadas e exterminadas.

O denominado homo sacer teve, na ditadura brasileira, raça, identidade de gênero e orientação sexual, assim como, em última instância, classe social, bem definidas. Evidentemente, a ficção universalista de Agamben (2007), por não considerar a existência de corporalidades mais valiosas do que outras, deixa de problematizar, com isso, os corpos que importam, que não correm o risco de serem expostos, ainda que em potência. Escamoteia-se o privilégio das vidas brancas, das vidas cis, das vidas heterossexuais, das vidas másculas, das vidas urbanas, das vidas que importam.

Uma análise do regime cis-hétero-militar brasileiro pelas lentes do aludido filósofo dificultaria, se não impediria, a problematização das vulnerabilidades específicas. É fundamental assinalar que houve singularidades com as vidas bichas, negras, mulheres, indígenas, camponesas na ditadura brasileira. Sem almejar, com isso, dar conta da totalidade das vulnerabilidades, o termo homossacralidade pretende apontar e destacar a "trans-lesbo-homo-vulnerabilidade" nesse regime, aqui considerado em suas transmutações intraestatais e não apenas circunscrito a seu suposto nível estatal. Assim como as relações de poder que a sustentam, a ditadura é uma complexa rede que vai do micro ao macro e vice-versa, em uma dinâmica de retroalimentação intraestatal.

Com esse termo, tento não recair na redução das dissidências sexuais e de gênero à homossexualidade masculina; de fato, busco sinalizar para a homogeneização imaginária (em mais uma das ambiguidades do prefixo homo) produzida por esse regime de sujeição como estratégia de bestialização dos sujeitos dissidentes da cisheteronormatividade, visto que era comum o uso, inclusive pelos órgãos formais, de termos animalizadores para se referir àquelas (bichas, viados). A homossacralidade como funcionamento do cistema sexo-gênero traduz o funcionamento deimopolítico presente na ditadura brasileira. 
Por deimopolítica (conceito proposto em minha dissertação AFONSOROCHA, 2020), compreendo o paradigma de governamento, por meio do qual se dá a produção do medo, mediante a personificação de inimigos imaginários. Esse funcionamento simbólico visa a mobilizar os afetos coletivos "em defesa da sociedade", justificando tanto o fundamento místico das autoridades quanto o apelo às configurações autoritárias. Nesse paradigma, a criação de inimigos desempenha função ecológica e sustentável. Para que a autoridade seja aceita, para que nos submetamos ao poder, precisamos temer algo. O que garante a ilusão contratualista é o medo e a esperança. Nessa lógica, o outro deve significar sempre uma ameaça, para que tenhamos o Estado como nossa última e única proteção. Para que isso se efetive no imaginário social, há uma fabricação deimopolítica de imagens de sujeitos, produzindo tanto sujeitos ameaçadores quanto sujeitos amedrontados. Por medo dos inimigos artificialmente inventados, aceitamos as instituições de integração do poder e legitimamos as mutilações necrobiopolíticas ${ }^{5}$ no corpo do outro. Dessa forma, não há estado de direito sem corpos inimigalizados, sem corpos de exceção.

Por isso, as ditas crises autoritárias não são exteriores ao funcionamento democrático, mas lhe são inerentes, imanentes e estruturais. O fascismo não é uma patologia do poder, não é algo externo desencadeado por situações anômalas. O fascismo serve à perpetuação da deimocracia ne(cro)oliberal, faz parte de sua normalidade. Serve como lembrança de que, mesmo com todos os "fracassos" e promessas não cumpridas, devemos defender a democracia liberal, ao passo que impede que sonhemos com possibilidades outras para além do paradigma de governamento capitalístico em sua forma ne(cr)oliberal. Nesse sentido, o autoritarismo é o outro da democracia, aquele que a sustenta, seja por assombro ou fascínio. No interior das democracias burguesas, pulsam configurações autoritárias. Tais configurações servem à perpetuação desse cistema de governo.

Em última instância, o fascismo é pedagógico: a mera possibilidade de sua reemergência "ensina-nos" a aceitar a autoridade ne(cr)oliberal, apaziguando as latentes tensões e contradições econômicas e sociais. Em sua pedagogização, o fascismo é resiliente. Assim funciona o que estou denominando de deimocracia ne(cr)oliberal: não

\footnotetext{
${ }^{5}$ Sobre o conceito de mutilações necrobiopolítica, ver Afonso-Rocha e Melo (2020).
} 
o governo do povo - essa entidade homogênea nunca teve existência real - mas como governamentalidade pelo medo e pela esperança. Afinal, pela produção deimopolítica, somos instados a acreditar que "o amanhã" será melhor, assim depositamos esperança na forma sujeito de direito. Isso serve à neutralização de qualquer potência revolucionária. O triunfo da esperança é a frustação da revolução (MELO, 2020).

Dessa forma, compreendo que a homossacralidade traduz um regime específico de sujeição familiar à deimopolítica, responsável por produzir sujeitos descartáveis, sem importância, como também produzir, imaginária e simbolicamente, sujeitos perigosos cuja animalidade significaria um risco social e biológico: uma periculosidade bichasapatrans. É como se inscrevesse no inconsciente o seguinte aviso: "CUIDADO, BICHAS”. Essa é a inscrição que garante e legitima a forclusão da diferença como resposta imunológica social.

O governo golpista reestruturou oficialmente o engenhoso cistema de controle moral, intensificado, pelo menos, desde a ditadura varguista com seus anseios nazifascistas. Por certo, houve a retomada, agora alçada e forjada em nível de políticas deliberadas de Estado, do controle moral das práticas dissidentes por meio da produção do cis-hétero-corpo reprodutivo. Penso ser esse o funcionamento discursivo e visível do cis-hétero-militarismo.

Não nego que, antes do regime autoritário, houvesse a produção sexual e de gênero em torno do cis-hétero-corpo, ou que, uma vez findo o período cinéreo, essa produção tivesse sido superada e, com ela, todo o aparato produtivo-repressivo desaparecesse. Contudo, sustento que, durante a denominada ditadura militar, houve singularidades em relação à significação das vidas bichas. Tais singularidades se tornam evidentes apenas quando analisamos as diversas formações históricas pelas quais as dissidências sexuais e de gênero foram significadas e dadas a ver desde o período colonial.

Com isso, não pretendo sustentar uma pretensa continuidade ou periodologia. Cada formação histórica (DELEUZE, 2017) funciona como ruptura: homogeneidades imaginárias que permitem e condicionam determinadas significações. Devemos sempre 
questionar: por que essas significações e não outras? ${ }^{6}$ Quais sentidos escapavam a esse funcionamento discursivo e visível? O que era possível dizer e ver para além da formação histórica em questão?

As formações históricas hegemônicas traduzem apenas os discursos hegemônicos e as visibilidades dominantes de uma dada época. ${ }^{7}$ A sua pretensa homogeneidade é um dos seus efeitos imaginários. Se uma formação histórica possibilita e potencializa o que pode e deve ser visto e dito, como também estabelece, em seu seio, o que deve e pode não ser dito e visto, devemos suspeitar que ela silencie visibilidades e enunciados não queridos, periféricos, contrários, subterrâneos, de resistência. Por isso, a necessidade de confrontar os locais de poder com os locais de resistência. Afinal, a formação histórica dominante em determinada região específica (a exemplo da crítica literária) cria a ilusão de que, naquela época, a qual supostamente "representa", inexistia outros sentidos, que o mundo era tal qual ela faz parecer ser. Para isso, apaga e silencia as formações históricas contra-hegemônicas, de modo a produzilas como exterioridades.

\section{Cis-hétero-militarismo}

Após essas considerações, cabe destacar que, ao utilizar o conceito deleuzeano (2017) de formação histórica, aponto para o entrecruzamento dos estratos que formam o saber: os enunciados e as visibilidades. São as condições por meio das quais as mentalidades se formulam e os comportamentos se manifestam em dada região e domínio específico, isto é, adentram no campo de inteligibilidade. Dessa forma, aquilo que é possível ver e falar em dada época sobre determinado objeto, prática ou sujeito decorre da pressurização das relações de poder dominantes, sendo, portanto, irrelevante questionarmos quem fala ou faz ver. Ou, como afirmou Foucault (1990), referenciando

\footnotetext{
${ }^{6}$ Aqui, refaço a pergunta feita por Foucault (2008): "por que esses enunciados e não outros?". Com meu gesto, busco o deslocamento do nível estrito do enunciado, tal qual posto em jogo com a pergunta de Foucault, para a relação enunciável/visível (formação histórica).

7 Quando utilizo o termo "época", tal qual comparece na análise de Deleuze (2017), tenho em consideração que "A arqueologia desarticula a sincronia dos cortes, como teria desfeito a unidade abstrata da mudança e do acontecimento. A época não é nem sua unidade de base, nem seu horizonte, nem seu objeto; se fala sobre ela, é sempre a propósito de práticas discursivas [e visíveis] determinadas e como resultado de suas análises". (FOUCAULT, 2008, p. 213).
}

Vol. 04, N. 13, Jan. - Abril, 2021 - http://periodicoscientificos.ufmt.br/ojs/index.php/rebeh/index 
Beckett, “que importa quem fala?". Na investigação arqueológica, importa apenas o Fala-se e o Vê-se. A impessoalidade que desloca o sujeito do local ilusório de iniciador do dizer para uma das modulações impessoais do "se" (FOUCAULT, 2008).

As formações históricas devem ser pensadas a partir de regiões específicas. Isso significa que só podemos analisar uma formação histórica em dado domínio do diagrama concreto do poder. Esse pensado na sua indissociável relação radical com o campo do saber. Por isso, o que tento aqui é apenas descrever as características gerais de um número limitado de transformações pelas quais foi possível descrever tanto a emergência quanto as transformações na norma específica de significação dos sujeitos cis-heterodissidentes. Para que tais formações se confirmem no espectro de dominância, a ponto de ser possível nomeá-las, tal qual a empreitada que aqui arriscadamente ensaio, seria preciso um estudo apartado sobre cada uma delas, de modo a descrever suas disposições, suas condições de aparição, suas regras de organização, bem como seus processos de derivações, de entrecruzamento, de transformações, de defasagens, de trocas, de analogias, de hierarquias, de contradições, de complementariedades, de coincidências.

Com isso, é preciso se distanciar de qualquer tentativa de periodização totalitária que reforçaria um "grande discurso/visibilidade" de uma época. Pelo contrário, a descrição das formações históricas tem seu funcionamento temporal mediado pela dominância e pela exterioridade, de tal forma que o grande discurso/visibilidade não passa de um dos seus efeitos de sentido. O que faz a formação histórica hegemônica? Ela busca produzir uma ilusão de homogeneidade, apagando as contradições, as diferenças e produzindo a resistência como exterioridade, de modo a criar um imaginário de que "[...] a partir de um certo tempo, todo mundo pensaria da mesma forma, apesar das diferenças de superfície, diria a mesma coisa, mediante um vocabulário polimorfo, e produziria uma espécie de grande discurso que se poderia percorrer indiferentemente em todos os sentidos" (FOUCAULT, 2008, p. 181).

É preciso desconfiar das evidências produzidas pelas formações históricas. É preciso interrogar os locais de poder e confrontá-los com os locais de resistência para assim tensionar o regime de dizibilidade e o campo de visibilidade que tenta se fazer dominante em dada formação social. Há confronto, relações de força, relações de 
dominância, há apagamento e silenciamento entre as distintas formações históricas. Há constante luta pela representação de uma época, de um objeto, de um domínio ou de uma região específica. Significamos nesse entremeio, nesse campo de batalha. Dessa forma, precisamos sempre situar a formação histórica descrita, não sendo possível sustentar qualquer formação histórica que não seja delimitada a dado domínio ou região. A própria ideia de representação de uma época é em si absurda, pois as formações históricas não ocorrem por meio de uma ruptura global. Com isso, devemos desvinculála da abstração (não há formação histórica de uma época ou de uma sociedade). Há formação histórica espaço e temporalmente demarcada num registro específico do saber-poder. Disso decorre que a formação histórica é pensada sempre em relação a.

A cadeia significante de singularidades, rupturas, descontinuidades e contradições não deve ser desprezada. Não há superação. O diagrama se movimenta, faz o signo deslizar (delirar) e funcionar como isto e aquilo ao mesmo tempo. Por isso, como Foucault, devemos construir nossa própria periodização. Como Mbembe, devemos desconfiar da periodização e da análise de Foucault. Aquilo que esse último desenhou na França, em seu belo enquadramento, não se aplica, inteiramente, aos países assaltados pela empresa colonial europeia. Nosso quadro é outro, nossas tintas e pincéis também. Embora toda periodização seja ilusória, não podemos deixar de ficcionalizar, visto que os corpos mutilados emergem pelas e nas formações históricas. Ou melhor, é pelas formações históricas que podemos entrever as linhas de subjetividade, ainda que pelas lentes de significação dominantes.

Devido ao entrecruzamento de visibilidades e enunciados, é impossível delimitar, com precisão, onde supostamente começaria ou terminaria dada formação histórica. A "origem", se é que existe, escapa-nos por conta da singularidade silenciosa de seu "aparecimento". No mais das vezes, uma formação surge décadas antes de se tornar hegemônica e poder ser visivelmente localizada em uma análise. Invocando Veyne (2011, p. 113), temos que reconhecer: "As origens raramente são belas; as realidades e as verdades se constroem pouco a pouco, por epigênese, e não são préformadas em germes.”. Já seu término, não passa de ilusão: ainda que não seja mais hegemônica, certamente alimenta outras formações e, volta e meia, pode comparecer, ainda que diferente, com força suscetível de intervir historicamente. 
Gostaria de fazer uma pequena digressão histórica para pensar o entrecruzamento das distintas formações históricas pelas quais as imagens dos sujeitos dissidentes emergiram. Antes da verborragia enunciativa, permitam-me apresentar um quadro resultante da minha análise, sob a ironia da tentativa de tornar visível aquilo que pretendo enunciar:

Quadro 1 - Formações históricas da dissidência sexual e de gênero no Brasil

\begin{tabular}{|c|c|c|c|c|c|}
\hline $\begin{array}{l}\text { Formação } \\
\text { histórica }\end{array}$ & $\begin{array}{l}\text { Regime de } \\
\text { enunciado }\end{array}$ & $\begin{array}{l}\text { Campo de } \\
\text { visibilidade }\end{array}$ & $\begin{array}{c}\text { Sujeito } \\
\text { Mutilado }\end{array}$ & $\begin{array}{c}\text { Paradigma de } \\
\text { governo }\end{array}$ & $\begin{array}{c}\text { Funcionamento } \\
\text { semântico }\end{array}$ \\
\hline $\begin{array}{l}\text { Pastoralis } \\
\text { mo sexo- } \\
\text { gendrado }\end{array}$ & $\begin{array}{l}\text { Pastoral } \\
\text { cristã } \\
\rightarrow \text { pecado }\end{array}$ & $\begin{aligned} & \text { Igreja } \\
& \rightarrow \text { pecador } \\
& \text { confesso }\end{aligned}$ & Sodomita & $\begin{array}{l}\text { Necropolítica da } \\
\text { carne }\end{array}$ & Demonização \\
\hline $\begin{array}{l}\text { Juridismo } \\
\text { sexo- } \\
\text { gendrado }\end{array}$ & $\begin{array}{l}\text { Direito Penal } \\
\qquad \begin{array}{l}\rightarrow \\
\text { delinquência }\end{array}\end{array}$ & $\begin{aligned} & \text { Prisão } \\
& \rightarrow \text { criminoso } \\
& \text { moral punido }\end{aligned}$ & Pederasta & $\begin{array}{c}\text { Anatomopolítica } \\
\text { do corpo }\end{array}$ & Criminalização \\
\hline $\begin{array}{l}\text { Psiquiatris } \\
\text { mo sexo- } \\
\text { gendrado }\end{array}$ & $\begin{array}{l}\text { Psiquiatria } \\
\rightarrow \text { desrazão }\end{array}$ & $\begin{array}{l}\text { Manicômio } \\
\rightarrow \text { louco moral } \\
\text { em tratamento }\end{array}$ & Pervertido & $\begin{array}{l}\text { Biopolítica da } \\
\text { população }\end{array}$ & Perversização \\
\hline $\begin{array}{l}\text { Cis-hétero- } \\
\text { militarismo }\end{array}$ & $\begin{array}{l}\text { Doutrina de } \\
\text { Segurança } \\
\text { Nacional } \\
\rightarrow \text { ameaça }\end{array}$ & $\begin{array}{l}\text { Esquina/Rua } \\
\rightarrow \text { inimigo } \\
\text { moral em ação }\end{array}$ & $\begin{array}{l}\text { Inimigo sexual } \\
\text { e de gênero }\end{array}$ & $\begin{array}{l}\text { Deimopolítica } \\
\text { do inimigo }\end{array}$ & Inimigalização \\
\hline
\end{tabular}

Fonte: Afonso-Rocha, 2020

O quadro aqui esboçado apresenta as formações históricas dominantes que enuncia(ra)m e torna(ra)m visível as dissidências sexuais e de gênero. É esse seu domínio, sua região específica. Não há formação histórica denominada pastoralismo, tal qual a proponho, para além da significação local, específica e singular da dissidência sexo-gendrada. Inexiste uma ruptura global de emergência e aparição de dada formação histórica. O que temos, em uma formação social delimitada, são distintas formações históricas entrelaçadas em diferentes níveis, domínios, regiões. Nesse entrecruzamento, 
há disputa por hegemonia. Sempre haverá os locais de resistência, memórias subterrâneas de outras formas de dizer e de ver. Espaços acontecimentais de registro das formações históricas impedidas de deixarem vestígios. Espaços que teimam em escancarar a temível heterogeneidade iconográfica e discursiva.

Pastoralismo sexual e de gênero. No período colonial, houve, no Brasil, uma série de políticas de repressão direta aos sujeitos vistos como cis-heterodissidentes, claro que, nos termos e nos limites que lemos hoje. As ações intraestatais se fundamentavam no que Foucault (2017) chamou de tecnologias da carne, gravitando em torno das ideias de pecado e de crime contra a natureza sagrada.

As Ordenações Filipinas, aplicadas no Brasil por mais de dois séculos, estabeleceram, em seu Livro V, Título XIII: Dos que cometem pecado de sodomia, e com alimárias, que:

[...] toda pessoa, de qualquer qualidade que seja, que pecado de sodomia por qualquer maneira cometer, seja queimado, e feito por fogo em pó, para que nunca de seu corpo e sepultura possa haver memória, e todos seus bens sejam confiscados para a Coroa de nosso Reino, posto que tenha descendentes: pelo mesmo caso seus filhos e netos ficarão inábiles e infames, assim como os daqueles que cometeram crime de Lesa-Majestade. (eu grifo).

Ou seja, a gravidade da sodomia ${ }^{8}$ equivalia àquele que era o crime mais dramático: traição contra sua majestade. Não é de se estranhar que até hoje, toda bicha atenta, em alguma medida, contra a dignidade do Soberano ou do Estado. Embora legislada, a sodomia dava a ver o atravessamento de um enunciado outro no jurídico ${ }^{9}$. Esse enunciado advinha da pastoral cristã, especificamente do Concílio de Trento (1545-1563), cujos direcionamentos demonstram ojeriza às práticas sodomitas.

Nisso, opera-se nitidamente aquilo que Mbembe (2018) chamou de necropolítica, acrescento, da carne; uma vez que, com tal funcionamento, a possibilidade da morte do sodomita faz ver sua carne de pecador, no intuito de impossibilitar que "de seu corpo e sepultura possa haver memória", conclamando a insensibilidade geral em relação a esse, cujo sofrimento nada mais é do que a expiação "necessária" do mal. Nessa lógica, a carne do pecador precisa sofrer, pois isso faria

\footnotetext{
${ }^{8}$ A sodomia praticada por mulheres era chamada de sodomia imprópria ou sodomia foeminarum.

9 Sobre a prática de sodomia durante a inquisição, consultar: Mott (2010), Vainfas (1989) e Novinsky (1983).
}

Vol. 04, N. 13, Jan. - Abril, 2021 - http://periodicoscientificos.ufmt.br/ojs/index.php/rebeh/index 
parte da purificação da alma. Mas, também, precisaria desaparecer, para não deixar vestígios dessa "existência infame". Por isso, é queimada. As cinzas não contam história.

A queima significa a destruição da matéria, a purificação do espírito e a aniquilação da memória. Tal forma de punição estava associada aos crimes de traição, heresia, bruxaria, incesto, sodomia. Dos elementos naturais, o fogo é aquele que mais fascínio despertou no ser humano. É pelo fogo eterno que Deus puniria os indignos, imorais e o próprio demônio. Pelas chamas viscerais, o divino mostraria seu poder:

Ao destruir com fogo, o homem brinca de ser Deus, dono do fogo da vida e da morte. E dessa maneira se identifica com um culto solar de purificação e com o grande mito da destruição [...] se queima um homem, ele é reduzido aos seus quatro elementos principais (carbono, hidrogênio, oxigênio e nitrogênio); se se queima o papel, a racionalidade intemporal deixa de ser racionalidade para se converter em cinzas. Além disso, há um detalhe visual. Quem viu algo queimado reconhece a inegável cor preta. O claro se torna escuro. (BÁEZ, 2006, p. 20).

Só pelas chamas, o mal seria expulso: "Malditos! Apartai-vos de mim. Ide para o fogo eterno, preparado para o Diabo e os seus anjos (MATEUS, 7: 23). Por isso, a queima dos sodomitas ou, mais tarde, de seus livros se revela como estratégia de construção da dissidência como ameaçadora. $\mathrm{O}$ fogo marca o corpo perigoso. A ameaça é tão elevada que é preciso destruí-las pelas chamas, ou nas palavras do Frei Felipe Moreira, cônego de Santo Agostinho:

Sodoma quer dizer traição. Gomorra, rebelião. É tão contagiosa e perigosa a peste da sodomia, que haver nela compaixão, é delito. Fogo e todo rigor, sem compaixão nem misericórdia! Tanta força tem o lugar apestado deste vício que para livrar dele até a um inocente, é necessário violência de muitos anjos. (apud MOTT, 2001, p. 54).

Para os sodomitas: "Fogo e todo rigor, sem compaixão nem misericórdia!", de forma a obliterar qualquer resquício dessa memória infame. Pelo fogo não se destrói apenas o objeto físico ou a matéria orgânica do dito inimigo, mas a memória, a marca de sua existência. As chamas impedem a memória. Findam os vestígios. 
Poderíamos traduzir esse funcionamento como a demonização do sodomita, cuja cadeia de signo produz a equação enunciativa ${ }^{10}$ : dissidência sexual e de gênero $=$ sodomia. Tal sinonímia será atualizada, integralizada e diferenciada pelos demais funcionamentos semânticos de nomeação dos sujeitos desviantes da (re)produtibilidade cis-heterossexista. Essa formação histórica (pastoral como enunciabilidade e igreja como visibilidade) constitui o que estou denominando pastoralismo sexo-gendrado: enuncia-se o pecado de sodomia e faz-se ver o cis-heterodissidente como sodomita, pecador confesso ou confessado.

Contrabandeio a noção de equação linguística de Bethania Mariani (1996) para pensar a equação enunciativa. Tal conceito põe em jogo a recorrência de sentidos produzida por uma série enunciativa (e visível, acrescento). Essa série traduz um processo de adjetivação necessária que "cola" sentidos naquilo que denomina, de modo que se estabelece uma correspondência sinonímica entre dois ou mais termos. A equação enunciativa é a correspondência entre o objeto e a denominação, cujo sentidos fixam um lócus semântico ontologizado no imaginário dos sujeitos como única possibilidade. Tal sinonímia emerge como uma evidência sempre já-lá. Com isso, qualquer enunciação ou descrição que escape ao esquadro dessa equação pertencerá ao indizível e ao não-visível, não apenas porque é censurada, mas porque, ainda que fosse dita e vista, não seria inteligível.

Juridismo sexual e de gênero. As Ordenações Filipinas vigoraram no Brasil até a elaboração do Código Penal do Império, publicado em 1830. O novo Código retirava a figura jurídico-moral da sodomia, não mais punível diretamente pelo Estado. A partir dessa normativa imperial, surgiram os crimes por ofensa à moral e aos bons costumes. De 1830 a 1940, teríamos a dimensão de inscrição hegemônica dos sujeitos cis-heterodesviantes por meio do direito penal, visto que o efeito de sentido negativo desses indivíduos era incentivado pelas instituições políticas e pelos órgãos oficiais, sobretudo, por meio de enunciados oriundos do sistema jurídico-penal.

As práticas cis-heterodesviantes foram enquadradas, ainda que obliquamente, na figura jurídica, vaga e estrategicamente imprecisa, de crime contra a moral. Por conta

\footnotetext{
${ }^{10}$ Suscetível de se materializar em distintas formulações linguísticas, em uma dada região de sentidos, e de determinar distintos quadros de visibilidade.
}

Vol. 04, N. 13, Jan. - Abril, 2021 - http://periodicoscientificos.ufmt.br/ojs/index.php/rebeh/index 
dessa abertura conceitual, os ditos crimes morais foram definidos pelos "aplicadores e executores" do sistema judicial: juízes, promotores e forças policiais. Funcionamento sociopolítico reiterado pelo Código Penal Republicano de 1890, no qual o "ilícito moral" apareceu como "crime contra a segurança da honra e honestidade das famílias" e como crime de "travestismo". Em 1932, o Código Penal Republicano foi reformado, surgindo a figura jurídica do crime de "ultraje ao pudor", visando a coibir a circulação de materiais impressos que supostamente ofendessem a moral e os bons costumes. Em 1940, promulgou-se mais um Código Penal, em vigor até hoje, que manteve o "crime moral", ainda que a sua rubrica seja outra.

É nesse período que se desenvolvem, ou, pelo menos, intensificam-se, no Brasil, os estudos criminológicos sobre a pederastia e sobre a "propensão" dos cisheterodesviantes a cometerem ilícitos penais. A vinculação entre dissidência sexual e de gênero com pedofilia também é produzida e intensificada por meio desses estudos. Desenvolve-se na esteira da teoria da delinquência. Além da necropolítica da carne, comparece a anatomopolítica do corpo. Se, antes, o binômio pastoral-igreja constituiu a formação histórica do pastoralismo sexual, aqui, o binômio direito penal/prisão traduz a formação histórica do juridismo ${ }^{11}$ sexo-gendrado.

O direito penal, como regime de enunciados, "diz" a delinquência sexual e de gênero: a pederastia; ao passo que a prisão, como campo de visibilidade, faz ver o criminoso sexual e gendrado punido. Podemos traduzir tal funcionamento como a criminalização do pederasta cuja cadeia significante põe em jogo a equação enunciativa (e visível) sodomia = pederastia, à medida que traz à tona, numa atualização paródica que repete, cita, desloca e reforça, a sinonímia dissidência $=$ sodomia.

Tal equação pode ser evidenciada na descrição do autor de medicina legal Jorge Jaime, de 1953. Para quem,

A sodomia trouxe e trará sempre consigo os germens da tragédia, do crime. Não se iludam, jovens adolescentes. Quando lhes falarem de 'uma felicidade celeste', de um 'gozo imortal', não acreditem. Eu vi a outra face do 'Amor

\footnotetext{
${ }^{11}$ Furtei a noção de juridismo de Suzy Lagazzy (1988), ainda que a autora não pense tal conceito como designação de uma dada formação histórica, nem o vincule às questões de sexualidade e de gênero. Não furto apenas o termo, mas a reflexão sobre o juridismo como funcionamento constitutivo que ultrapassa os aparelhos estatais e jurídicos formais.
}

Vol. 04, N. 13, Jan. - Abril, 2021 - http://periodicoscientificos.ufmt.br/ojs/index.php/rebeh/index 
Socrático' e lhes asseguro que é horrenda, monstruosa [...] O pederasta é um criminoso consumado. Atenta contra a moral pública nos cinemas, rouba nas casas comerciais, assassina nos quartos fechados e usa de meios secretos para perpetrar injúria, difamação e calúnia. (apud GREEN; POLITO, 2006, p. 92-3, eu grifo).

Psiquiatrismo sexual e de gênero. A partir de 1900, ${ }^{12}$ com o desenvolvimento da clínica e do hospital psiquiátrico, da medicina legal e da criminologia, vemos emergir outra formação histórica, a que denomino psiquiatrismo sexo-gendrado. ${ }^{13}$ Essa formação "começa" a se desenvolver, entre nós, com o projeto médico-higienista do século XIX, muito em virtude da vinda da Corte Portuguesa para o Brasil, que resultou na criação de uma política de higienização para o país. Contudo, só romperá o limiar político, passando a fornecer hegemonicamente os prismas enunciativos e de visibilidades para uma multiplicidade de formações discursivas e não-discursivas após 1930. Atrelada à teoria da delinquência, desenvolve-se a teoria da degenerescência, que buscou explicar a dissidência como perversão ou mau funcionamento biológico. Cabe destacar as políticas higienistas lombrosianas implementadas pelo governo Vargas, em especial nas ações do médico Leonídio Ribeiro, que procurou demonstrar supostas relações entre a homossexualidade masculina e o funcionamento endócrino irregular. Em seu estudo, Ribeiro chegou a medir partes do corpo de centenas de presos no Rio de Janeiro em 1932.

O desviante sexual e de gênero não é apenas o sodomita, o pederasta, mas é também o pervertido inscrito hegemonicamente no paradigma biopolítico da população. “Agora”, é a família que se encontra ameaçada. Com a perversivização das dissidências, comparece o regime de enunciado da psiquiatria e da medicina legal; e o campo de visibilidade do manicômio. Tal formação histórica enuncia a desrazão sexual e de gênero e faz ver o pervertido em tratamento. A cadeia significante traduz a equação

\footnotetext{
${ }^{12}$ Alerto para a ficcionalidade de qualquer periodização. Elas servem apenas para auxiliar na construção espaço-temporal das formações históricas. Devemos ter em mente que as formações históricas constroem sua homogeneidade imaginária como forma de apagar a heterogeneidade constitutiva e passar como "representações" de uma época. Por exemplo, desde 1784, com a publicação do livro de Medicina Theologica, de Francisco de Melo Franco, constatamos a emergência, no Brasil, da racionalidade médicopsiquiátrica que desembocará na abordagem da dissidência sexual e de gênero como perversão (BUTTURI JÚNIOR, 2012).

13 Aqui, faço menção ao que Robert Castel (1978) denominou psicanalismo: o efeito produzido pela psicanalização do cotidiano.
}

Vol. 04, N. 13, Jan. - Abril, 2021 - http://periodicoscientificos.ufmt.br/ojs/index.php/rebeh/index 
pederastia $=$ perversão, atualizando os efeitos sinonímicos dissidência $=$ sodomia $\mathrm{e}$ sodomia $=$ pederastia .

É dessa formação histórica que emergem os enunciados e as visibilidades sobre o "homossexual" como espécie de perversão. Tal funcionamento biopolítico pode ser observado na descrição do médico José Ricardo Pires de Almeida, em 1906:

O invertido deveria ser acompanhado desde a infância, vigiado por uma espécie de tutor que, à feição de um aparelho ortopédico moral, fosse-lhe obstáculo ao desvio, trabalhando pertinentemente para que a consolidação se efetue em absoluto. (...) Antes de tudo, devemos lembrar que tais desregramentos são puramente moléstias mentais; e por isso, aconselharei, quando não tenhamos acompanhado o indivíduo desde a infância, e hajamos iniciado o tratamento em idade tardia, medicá-lo pela estética sugestiva. (apud GREEN; POLITO, 2006, p. 97, eu grifo).

Cis-hétero-militarismo. A partir de 1960, com a "ditadura militar" (ou melhor, cis-hétero-militar), ao lado do pilar eclesiástico - significado pela ideia de Deus - a família e a nação compareceram com força nos enunciados da Doutrina de Segurança Nacional (DSN). Tais signos (Deus-família-nação) correspondiam ao lema levantado nas insignes manifestações públicas ocorridas durante 1964, em apoio ao golpe civil-militar. Nesse período, a dissidência sexo-gendrada passou a ser produzida hegemonicamente como ameaça à sociedade em sua integralidade e não somente ao Estado (juridismo), à família (psiquiatrismo) ou à religião (pastoralismo). O que estava em jogo, nesse funcionamento deimopolítico, era o futuro integral da espécie, seus valores, suas tradições, sua história, sua forma de vida, sua cultura - a possibilidade mesma do futuro.

A imagem do sujeito cis-heterodissidente passa a emergir, hegemonicamente, de uma inscrição polimorfa oriunda da bipolarização geopolítica entre a URSS e os EUA. Surgem os inimigos sexo-gendrados, numa estratégia que produzia a associação necessária e insuperável entre comunismo e devassidão moral. Plano enunciativo que remonta a 1930 (COWAN, 2015), com as ideias integralistas reacionárias, baseadas numa suposta tentativa de desestruturação das famílias cis-heterocentradas como forma tática de levar a cabo revoluções comunistas no Ocidente.

Como, por exemplo, é possível interpretar no informe confidencial de 08 de julho de 1987, que trazia informações sobre possíveis militantes do PCB, no qual 
consta: "JOSÉ ANTÔNIO CARVALHO DE MESQUITA é homossexual assumido, fazendo parte da 'Ala Gay' do PCB e sendo comum seu contanto com menores de idade, notadamente estudantes, aos quais procura disseminar as idéias do Partido." (BRASIL/SNI, 1987, p. 2, eu grifo). Ou ainda no Informe $n^{\circ} 2896$ sobre Frei Severino Batista de França, segundo o qual: "Frei SEVERINO é elemento de tendência esquerdista e de moral duvidosa, pois no meio religioso é considerado como homossexual devido ao seu comportamento ao lidar com jovens paroquianos." (BRASIL/SNI, 1983b, p. 1, eu grifo).

Nesses episódios, percebemos a tentativa de comprovar as famigeradas relações entre comunismo e dissidência moral. Algumas notícias alimentadas pelo Sistema Nacional de Informações buscavam demonstrar a existência de relações, ainda que eventuais, entre militantes do $\mathrm{PCB}$ e os ditos subversivos sexuais e de gênero: "O travesti 'ROBERTA CLOSE'[...] é irmão de ROBERTO ANTÓNIO GAMBINI MOREIRA, militante do PARTIDO COMUNISTA BRASILEIRO/RJ (PCB/RJ) com curso na Escola do KONSCMOL, em MOSCOU, em 1982” (BRASIL/SNI, 1984, p. 1). Tal funcionamento deimopolítico servia à reatualização da ameaça comunista pela suposta estratégia de destruição da "família, dos valores cristãos e da nação".

O inimigo moral seria, assim, efeito da significação mítica, cujo significado flutuaria, atualizando significantes outros, oriundos de formações históricas diversas, constituindo, ao mesmo tempo: o sodomita, do plano de imanência religioso; $o$ pederasta, no criminológico-penal, e o pervertido, no médico-psiquiátrico. Contudo, como seu funcionamento é mítico, e não apenas linguístico, há mais que considerar. A equação mítica traduz a possibilidade de os inimigos cis-heterodissidentes significarem além e aquém desses significantes. Sendo significadas como ameaça integral, as dissidências são produzidas pelo processo de inimigalização. O cis-hétero-militarismo, como formação histórica, enuncia a ameaça moral e faz ver os inimigos morais. A cadeia significante traduz a equação mítica dissidências sexo-gendradas = ameaça. Como a ameaça comporta as demais correspondências semânticas, a atualização das demais formações históricas lhe é inerente e imanente.

Com efeito, é nessa formação histórica que teríamos a homossacralidade como regime de sujeição das vidas bichas. É possível ver esse funcionamento deimopolítico 
na edição $\mathrm{n}^{\mathrm{o}}$ 6, do jornal Afinal, de 1980, no texto de Sérgio A. F. Rubim, intitulado

"Recado das bichas à polícia e aos seus espancadores: "não é desse tipo de pau que a gente gosta"”, no qual relata sobre a formação de um grupo que sequestrava e espancava gueis e travestis em Florianópolis:

[...] começou, em Florianópolis, uma verdadeira campanha de violência desencadeada contra prostitutas e homossexuais, envolvendo desde policiais até grupos organizados. Durante as sessões de espancamentos os tarados manifestam sua ideologia de preservação da 'família, da moral e das tradições'. Vários outros casos aconteceram. E todos os agredidos deixam claro que foram alvos de um grupo organizado que, em nome da propriedade e da moral, espancam com a certeza de que não serão punidos. [...] Marginalizados e discriminados pela sociedade, os homossexuais não procuram a polícia ou a imprensa para denunciar as agressões. Alegam não acreditar que as instituições lhes protejam e também temem sofrer represálias. Em relação aos órgãos de comunicação, sabem que as grandes empresas jornalísticas só se interessam por fatos como esses para fazer sensacionalismo, sem nunca se preocupar em defender o direito de prostitutas e homossexuais se manifestarem livremente. (p.14).

Em 1986, o Serviço de Censura de Diversões Públicas emitiu parecer pela liberação da peça "Rapazes", de Ronaldo Reis, cuja personagem principal era uma travesti. A liberação da peça que tratava de temas morais foi justificada da seguinte forma:

Os problemas abordados na obra, como homossexualismo, aborto, prostituição e consumo de drogas estão plenamente integrados ao contexto da mesma. Não existe apologia a estes tipos de comportamentos, mas sim uma crítica mostrando a decadência física e mental acarretadas pelos mesmos. (BRASIL/ SCDP, 1986, p. 57).

Já a peça "Carnaval 69", de Dalmo Vicenti, que colocaria em cena três travestis, foi censurada, em 1969, sob a justificativa de ser "[...] mais uma das muitas chanchadas imorais destinadas ao chamado teatro-revista. Diálogos do mais baixo nível, capazes de conduzir pela marcação ou através de gestos previamente ensaiados, a cenas mais imorais, indecorosas, pornográficas e irreverentes [...]”. E arremata: “[...] nada tem de arte, nem de teatro, mas, ao contrário, é vazia, situa-se abaixo do medíocre e não apresenta nenhuma mensagem válida" (BRASIL/SNI, 1969, s.p.).

Estamos diante de uma equação mítica, na qual as dissidências são simbolizadas e imaginarizadas como inimigø polimorfo. O símbolo ø (vazio) serve para sinalizar esse significante que se desdobra sobre si, flutuando entre outros significantes

Vol. 04, N. 13, Jan. - Abril, 2021 - http://periodicoscientificos.ufmt.br/ojs/index.php/rebeh/index 
numa cadeia infinitesimal. Como é possível ver, a partir dos episódios narrados, as dissidências são significadas como ameaça à nação. Inclusive, a acunha de "homossexual" serve como acusação: "consta ser homossexual", "moral duvidosa". Para que esse funcionamento deimopolítico se efetive, produz-se uma relação de sinonímia entre comunista e "homossexuais".

Como efeito disso, temos os reiterados mecanismos de sacralização das corporalidades bichas, concretizados nas campanhas de violências como a de Florianópolis cujos agressores "espancam com a certeza de que não serão punidos", pois ali estavam diante de sujeitos produzidos como indignos, corpos sem peso ou importância. Aí vemos o funcionamento deimopolítico da homossacralidade: "Reprimidas, ameaçadas, sem contar com o apoio de praticamente ninguém e sem direito nem mesmo à proteção policial” (RUBIM, 1980, p. 14).

Já no episódio da liberação da peça por supostamente mostrar a decadência moral sem fazer apologia, vemos operar a significação negativa das dissidências. Em paráfrase, temos: "é permitido a presença de personagens LGBT+, desde que os retrate de modo caricato, estereotipado e fique claro que aquele comportamento é antinatural e representa uma afronta moral aos ideais revolucionários".

Como efeito, a equação não é marcada apenas pela equivalência entre significantes, mas pelo esvaziamento semântico do signo. Ou seja, como metáfora, já que não é só a forma de conteúdo (o sentido ou sema/semantema), mas já um signo conotado, em que um signo se refere a um significado, havendo justaposição na cadeia aberta de significados em relação ao significante, o que caracteriza, localmente, a metáfora, a conotação.

Além da necropolítica da carne, da anatomopolítica do corpo, da biopolítica da população, teríamos sua inscrição hegemônica a partir da deimopolítica do inimigø. Ao enunciar e fazer ver os sujeitos em perigo, bem como suas ameaças (os inimigøs morais), o cis-hétero-militarismo traduz o fundamento místico da autoridade (DERRIDA, 2010): em defesa da sociedade dita normal, "precisamos" das instituições fortes, capazes de proteger-nos dos riscos das abjeções que habitam nossa sociedade. De certo modo que os sujeitos não reconhecidos como plenamente humanos servem à justificação da autoridade. 
Assim, a continuidade do funcionamento institucional depende da diferenciação entre cidadão amedrontado e inimigø amedrontador. Nessa lógica, o outro não pode ser humano, precisa ser diferente de "nós". Caso contrário, havendo reiteradas identificações, esse funcionamento poderia ruir, afinal, notaríamos que a humanidade não é algo inerente, mas relacional, ficção que pressupõe zonas abjetas fundantes. A deimopolítica faz ver e faz falar a sociedade "normal", o assim denominado cidadão de bem como sujeito amedrontado; como também enuncia e faz ver as "anormalidades", aqueles que supostamente deveríamos temer.

Se a DSN enuncia a ameaça moral, aquele ser sombrio, sem confiança, que amedronta e fascina; é a esquina ou a rua, espaço urbano, simbólico-imaginário, que inscreve hegemonicamente seu campo de visibilidade: é preciso que esse inimigø seja visto. A esquina, como campo de visibilidade no cis-hétero-militarismo, faz ver o risco, transformando em ato aquela potência ameaçadora enunciada pela DSN.

Devemos questionar: quem habita a esquina? Depravados sexuais, monstros, bestas sedentas, imundas existências significadas apenas pelos vícios. Metáfora (e metonímia) que define o local de visibilidade do inimigø, a esquina torna visível quais sujeitos devem ser temidos. Habitou a esquina, não pode ser reconhecido como cidadão de bem.

Se o psiquiatrismo produz o pervertido como aquele que deve temer a sociedade, isto é, amedronta o louco, visto que faz vê-lo em tratamento, assim como o pastoralismo mostra o sodomita confesso e o juridismo produz, em seu campo de visibilidade, o pederasta punido; o cis-hétero-militarismo faz exatamente o oposto: produz o inimigø como aquele que deve ser temido, mostra-o em cena, agindo na imoralidade.

O dito inimigø deve causar medo. Devemos temê-los. A sociedade deve ser amedrontada. A esquina faz ver o inimigø em ação. O tempo da ameaça é o presente. Enquanto as outras formações históricas enunciam e fazem ver a força das instituições, visto que nos apresentam a ameaça sob o controle das autoridades (igreja, família e Estado), o cis-hétero-militarismo enuncia e faz ver a "fraqueza" do Estado, da sociedade e dos cidadãos, de modo a justificar e fundamentar a necessidade das ações mortíferas. 
Com efeito, é esse o funcionamento da homossacralidade como regime de sujeição da deimopolítica.

\section{Uma pequena consideração}

A partir de Deleuze (2017), penso a esquina como um não-lugar constituído por pontos de atravessamentos. A esquina é tomada, então, como possibilidades de encontros e desencontros. Na esquina, não há entradas ou saídas, apenas passagens plurais. Não há começo ou fim. Há apenas conjunto de pontos recortados, atravessados, entrecruzados que emergem a partir de um regime de luz e de escuridão.

Por tal regime, a esquina é o lugar da sombra, da escuridão, da ininteligibilidade. É o lugar da ameaça. Espaço supostamente habitado por bestialidades e monstruosidades. É nesse sentido que penso que a esquina recorta a memória em silêncios. Ali transitam os corpos destinados a não deixar rastros. Os corpos impedidos de fazerem memórias. A esquina diz (desdiz) o silêncio da cidade, essa pensada como territorialidade simbólico-imaginária, e não necessariamente empírica, que faz ver as relações de poder.

Por isso, como campo de visibilidade do cis-hétero-militarismo, a esquina carrega singularidades inimagináveis em outras formações históricas, com seus campos de visibilidades fechados (igrejas, hospícios, prisões) e quase que absorvidos, por completo, pelas tramas do poder. Diferente da igreja, da prisão e do hospital psiquiátrico, a esquina se pluraliza, mais facilmente, em espacialidades contestatórias. Sua temporalidade é polivalente. Ao mesmo tempo em que faz ver a ameaça, a esquina se transmuta em espaço de solidariedade, de afetos, de encontros, de respiração dos gozos proibidos. Converte-se em subterrâneo existencial. A esquina constitui um museu flutuante das memórias impossíveis.

Ao mostrar a ameaça social, paradoxalmente, produz-se uma relação territorial de identificações múltiplas. Para aqueles colocados em evidência pela esquina, aquele espaço de abjeção constitui vínculos contra-hegemônicos: os oprimidos habitam a esquina. Na esquina, vivem, amam, gozam, sofrem, sentem, se queixam, se organizam, 
contestam, resistem. Na esquina: falta da luz como laço social fundado na nossa similar vulnerabilidade.

A luz existe pela sua ausência: a não-luz, as sombras, as zonas de penumbra. $O$ dito existe pela sua ausência: o não-dito, os silêncios, o por dizer... Nossos rastros infames gozam e latejam pulsantes nesse não-lugar, que se impõe pelos indizeres e obscuridades. O vazio significa. É revolucionário. A esquina faz o risee da bicha eterno. Afinal, o risee das bichas é a possibilidade de risear e arrisear: as bichas são ariseas! O risce das bichas? $\mathrm{O}$ habitar a esquina. $\mathrm{O}$ traço vertiginoso grafitado numa parede recémpintada. O incômodo desmensurado que serve para lembrar-nos que nossas certezas são ficções securitizadas.

Com Jacques Derrida (1973), aprendi que a rasura pode colocar em jogo a desconstrução do traço: a luta pelo desaparecimento na imagem que o traço traça pela diferença. Marca que transmuta qualquer inscrição universal, o traço articula os signos entre si. A linguagem é rasurada. Todo significado está sob rasura. A transparência da linguagem não passa de delírio banal. Por não aceitarmos a incompletude, as contradições, a imperfeição, a inexistência das identidades, esforçamo-nos a construir margens. Estamos sempre a lutar contra a rasura. Por isso, um termo rasurado, como risee, pretende apontar para ficção da identidade, para a ilusão dos universais, potencializando sentidos outros que escapam à transparência unívoca reclamada pela não-contradição. Pensar a experiência das sexualidades e dos gêneros dissidentes sob rasura do risee (que se risca), significa reconhecer a polivalência discursiva e nãodiscursiva na constituição dessa experiência, significa reconhecer posições que questionam e contestam as ilusões da adequação, do universal, do racional e do transcendental. Significa habitar a esquina.

O risee da bicha é imanente ao seu risear. O risee das bichas: o traço constitutivo da diferença. Bicha: risee, risea, arrisea... arisea! O risear é a bicha bichando o poder pelo traço.

\section{Referências}

AFONSO-ROCHA, Ricardo. Bichas também sangram: Deimopolítica e direito de resistência na literatura "homossexual" do jornal Lampião da Esquina. Dissertação - (Mestrado em Letras). 
Programa de Pós-Graduação em Letras: Linguagens e Representações, Universidade Estadual de Santa Cruz, Ilhéus, 2020.

AFONSO-ROCHA, Rick; MELO, Iago Moura. Mutilações necrobiopolíticas em os transparentes, de Ondjaki. Revista Mulemba, v. 12, n. 22, p. 183-199, 2020.

AGAMBEN, Giorgio. Homo Sacer: o poder soberano e a vida nua. Tradução de Henrique Burigo. Belo Horizonte: Editora da UFMG, 2007.

BÁEZ, Fernando. História universal da destruição dos livros: das tábuas sumérias à guerra do Iraque. Rio de Janeiro: Ediouro, 2006.

BENEVIDES, Bruna G. Post no Facebook. [Tensiona a utilização do termo homossexualidades]. Niterói, 29 de novembro de 2020. Facebook: BrunaMBenevides. Disponível em: <https://www.facebook.com/BrunaMBenevides/posts/4701070423296282>. Acesso em: 30 nov. 2020.

BENTO, Berenice. Necrobiopoder: Quem pode habitar o Estado-nação? Cadernos Pagu, n. 53, 2018.

BRASIL. Análise de Propaganda Adversa: Jornal 'Afinal', nº 06, de out./1980. Fundo: Divisão de Segurança e Informações do Ministério da Justiça, 12 de novembro de 1980. (BR RJANRIO TT.0.MCP, AVU.451).

BRASIL. Comissão Nacional da Verdade. Ditadura e homossexualidades. Brasília: CNV, 2014.

BRASIL. Serviço de Censura de Diversões Púbicas. Laudo censório: Carnaval 69, de Dalmo Visconti. Brasília, 02 de janeiro de 1969. (BR DFANBSB NS.CPR.TEA, PTE.236).

BRASIL. Serviço de Censura de Diversões Públicas (SCDP). Censura prévia: peças teatrais. Parecer n. 279 (Análise de Rapazes de Ronaldo Reis). Rio de Janeiro, 20 de maio de 1986 (BR RJANRIO TN.CPR.PTE.3806).

BRASIL. Serviço Nacional de Informação (SNI). Informe militantes do PCB. [S.L.], 8 de julho de 1987 (BR DFANBSB V8.MIC, GNC.LLL.87007106).

BRASIL. Serviço Nacional de Informação (SNI). Informe $\mathbf{n}^{\mathbf{0}} \mathbf{2 8 9 6}$ sobre Frei Severino Batista de França. Agência SNI-Central, 08 de novembro de 1983b. (BR DFANBSB V8.MIC, GNC.AAA.84039134)

BRASIL. Serviço Nacional de Informações (SNI). Informe $\mathbf{n}^{\mathbf{0}} 090$ (Sobre Roberta Close). Agência do Rio de Janeiro, 04 de julho de 1984. (BR DFANBSB V8.MIC, GNC.CCC.84010978).

BUTLER, Judith. Corpos que importam: os limites discursivos do "sexo". São Paulo: N-1; Crocodilo edições, 2019. 
BUTLER, Judith. Quadros de guerra: quando a vida é passível de luto. Rio de Janeiro: Civilização Brasileira, 2015.

BUTTURI JUNIOR, Atílio. A passividade e o fantasma: o discurso monossexual no Brasil. 2012. 280f. Tese (Doutorado em Linguística) - Universidade Federal de Santa Catarina, Florianópolis, 2012.

CARVALHO, Flávio. O golpe da princesinha. Afinal, Florianópolis, nº 12, maio de 1981.

CASTEL, Robert. O psicanalismo. Rio de Janeiro: Edições Graal, 1978.

COWAN, Benjamin. Homossexualidade, ideologia e subversão no regime militar. In: GREEN, J; QUINALHA, R. (Orgs.). Ditadura e homossexualidades: repressão, resistência e a busca da verdade. São Carlos: EdUFSCAR, 2015.

DE OTO, Alejandro; QUINTANA, María Marta. Biopolítica y colonialidad. Una lectura crítica de Homo sacer. Tabula Rasa, n. 12, p. 47-72, 2010.

DELEUZE, Gilles. Michel Foucault: as formações históricas. São Paulo: N-1 edições; Politeia, 2017.

DERRIDA, Jacques. Gramatologia. Trad. Miriam Schnaiderman e Renato J. Ribeiro. São Paulo: Perspectiva, 1973.

DERRIDA, Jaques. Força de lei: o fundamento místico da autoridade. Tradução de Leyla Perrone-Moisés. 2. ed. São Paulo: Martins Fontes, 2010.

FOUCAULT, Michel. A arqueologia do saber. Tradução de Luiz Felipe Baeta neves. Rio de Janeiro: Forense Universitária, 2008.

FOUCAULT, Michel. História da Sexualidade 1: a vontade de saber. Tradução de Maria Thereza da Costa Albuquerque e J. A. Guilhon Albuquerque. Rio de Janeiro: Paz e Terra, 2017.

FOUCAULT, Michel. O pensamento do exterior. São Paulo: Princípio, 1990.

GREEN, James; POLITO, Ronald. Frescos trópicos: fontes sobre a homossexualidade masculina no Brasil (1870-1980). Rio de Janeiro: José Olympio, 2006.

HEIDEGGER, Martin. Ser e Tempo. Tradução de Márcia de Sá Cavalcanti. Petrópolis: Vozes, 1989.

LAGAZZY, Suzy. O desafio de dizer não. São Paulo: Pontes Editores, 1988.

LENTIN, Ronit. Femina sacra: Gendered memory and political violence. Women's Studies International Forum. Pergamon, p. 463-473, 2006.

MARIANI, Bethânia. O comunismo imaginário: práticas discursivas da imprensa sobre o PCB (1922-1989). Tese - (Doutorado em linguística). Universidade de Campinas, 1996.

Vol. 04, N. 13, Jan. - Abril, 2021 - http://periodicoscientificos.ufmt.br/ojs/index.php/rebeh/index 
MBEMBE, Achille. Necropolítica: biopoder, soberania, estado de exceção, política da morte. Tradução de Renata Santini. São Paulo: n-1 edições, 2018.

MELO, Iago Moura. O triunfo da esperança. In: SILVA, Jairo da Silva e (Org.). Narrativas em quarentena: emergências do agora, incertezas do amanhã. Ananindeua, PA: Itacaiúnas, 2020, v., p. $39-46$.

MOTT, Luiz. A revolução homossexual: o poder de um mito. Revista USP, n. 49, p. 40-59, 2001.

MOTT, Luiz. Bahia: Inquisição e sociedade. Salvador: EdUFBA, 2010.

NOVINSKY, Anita. A inquisição. [S.L.]: Brasiliense, 1983.

PEREIRA, Pedro Paulo Gomes. Queer decolonial: quando as teorias viajam. Revista Semestral do Departamento e do Programa de Pós-Graduação em Sociologia da UFSCar, v. 5, n. 2, p. $411,2015$.

RUBIM, Sérgio A. F. Recado das bichas à polícia e aos seus espancadores: 'não é desse tipo de pau que a gente gosta'. Afinal, Florianópolis, $\mathrm{n}^{\circ}$ 6, de outubro de 1980. In: BRASIL. Análise de Propaganda Adversa: Jornal 'Afinal', n ${ }^{\circ}$ 06, de out./1980. Fundo: Divisão de Segurança e Informações do Ministério da Justiça, 12 de novembro de 1980. (BR RJANRIO TT.0.MCP, AVU.451).

SÃO PAULO. Comissão Estadual da Verdade Rubens Paiva. Ditadura e homossexualidades. São Paulo: CEVSP, 2015.

VAINFAS, Ronaldo. Trópico dos pecados: moral, sexualidade e inquisição no Brasil. [S.L.]: Ed. Campus, 1989.

VEYNE, Paul. Foucault: seu pensamento, sua pessoa. Rio de Janeiro: Civilização Brasileira, 2011.

VIDARTE, Paco. Ética bixa: proclamações libertárias para uma militância LGBTQ. São Paulo: N-1 edições, 2019.

ZIAREK, Ewa. Bare life on strike: Notes on the biopolitics of race and gender. South Atlantic Quarterly, v. 107, n. 1, p. 89-105, 2008.

\section{Homosacrality as a regime for the subjection of queer lives}

Abstract: Since I started my research on the meaning of the queer body during the Brazilian cis-hetero-military dictatorship, as I call it, the thought of the Italian philosopher Giorgio Agamben has served as an analytical support. For a while, it seemed to me that Agambenian analysis, especially that on homo sacer, was an 
interesting tool for thinking about queer existences under the lead years. However, the more I took these singularities into account, the more I realized the inconsistencies of my frustrated attempt at subsumption. Over time, I could see that Agamben let the social particularities inherent to the declaration, by the sovereign, of the nakedness of a life escape. In his reading, the homo sacer would be universal: we could all be abandoned or sanctified by the sovereign. Its generalization erased the marks of the processes that separate the bodies destined to live, from those corporalities marked as unimportant lives. Or rather, bodies that could be exposed to the possibility of death, including violent ones, whose deaths do not arouse mourning or social compassion. Agamben despised the deimo-bio-necropolitical management of the unwanted, in such a way that the place he spoke of appeared, albeit by default: man, cis, straight, white, western. Inhabiting an intelligibility zone, the theorist lacks a closer look at concrete subjects. In another direction, to think of the singularities in relation to queer existences during the cis-hetero-dictatorial context, I formulated the notion of "homosacrality", as a regime of subjection linked to the governance paradigm of deimopolitics. To delineate these specificities, I trace, provisionally and imaginary, a picture of the different historical formations of significance of the sex-gendered dissent in Brazil.

Keywords: Deimopolitics. Biopolitics. Necropolitics.

Recebido: 16/02/2021

Aceito: 01/04/2021 